\title{
THE INFLUENCE OF IMPACT SPEED ON CHEST INJURY OUTCOME IN WHOLE BODY FRONTAL SLED IMPACTS
}

\author{
Sen $\mathrm{XIAO}^{1,2^{\star}}$, Fuhao $\mathrm{MO}^{3}$, Jikuang $\mathrm{YANG}^{2,4}$, Jing $\mathrm{HUANG}^{5}$, Zhi XIAO ${ }^{6}$, Jeff R. CRANDALL ${ }^{7}$ \\ ${ }^{1}$ School of Mechanical Engineering, Hebei University of Technology, Tianjin, China \\ 2,3,5,6 State Key Laboratory of Advanced Design and Manufacture for Vehicle Body, Hunan University, Changsha, China \\ ${ }^{4}$ Dept of Applied Mechanics, Chalmers University of Technology, Gothenburg, Sweden \\ ${ }^{7}$ Centre for Applied Biomechanics, University of Virginia, Charlottesville, United States
}

Received 25 July 2016; revised 25 December 2016, 13 March 2017; accepted 6 April 2017

\begin{abstract}
While the seatbelt restraint has significantly improved occupant safety, the protection efficiency still needs further enhance to reduce the consequence of the crash. Influence of seatbelt restraint loading on chest injury under $40 \mathrm{~km} / \mathrm{h}$ has been tested and documented. However, a comprehensive profiling of the efficiency of restraint systems with various impact speeds has not yet been sufficiently reported. The purpose of this study is to analyse the effect of the seatbelt loadings on chest injuries at different impact speeds utilizing a high bio-fidelity human body Finite Element (FE) model. Based on the whole-body frontal sled test configuration, the current simulation is setup using a substitute of Post-Mortem Human Subjects (PMHS). Chest injury outcomes from simulations are analysed in terms of design variables, such as seatbelt position parameters and collision speed in a full factorial experimental design. These outcomes are specifically referred to strain-based injury probabilities and four-point chest deflections caused by the change of the parameters. The results indicate that impact speed does influence chest injury outcome. The ribcage injury risk for more than 3 fractured ribs will increase from around 40 to nearly $100 \%$ when the impact speed change from 20 to $40 \mathrm{~km} / \mathrm{h}$ if the seatbelt positioned at the middle-sternum of this study. Great injuries to the chest are mainly caused by the change of inertia, which indicates that chest injuries are greatly affected by the impact speed. Furthermore, the rib fracture risk and chest deflection are nonlinearly correlated with the change of the seatbelt position parameters. The study approach can serve as a reference for seatbelt virtual design. Meanwhile, it also provides basis for the research of chest injury mechanism.
\end{abstract}

Keywords: impact speed, seatbelt loading, chest injury outcomes, computational biomechanics, fracture risks.

\section{Introduction}

Chest injury is one of the most common injuries among vehicle accident injuries. In addition, the incidences of serious chest injuries are 5.5 and 33\% in National Automotive Sampling System (NASS) and Crash Injury Research and Engineering Network (CIREN). Among the study samples, 59.3 are male and $40.7 \%$ are female. However, $57.5 \%$ are restraint when the accident happened (Nirula, Pintar 2008). Moreover, chest injury also makes up of $13 \%$ of moderate injuries in vehicle accidents (Ruan et al. 2003). At the same time, rib fracture is the major and most common form of chest injuries that can result in mortality and severe morbidity (Baker et al. 1974; Kent, Patrie 2005) and the location of the rib fracture may reflect the direct link between the injuries of ribcage and inner organs (Nahum, Melvin 2002). Rib fracture as well as costal cartilage fracture are generally happened in the chest injury cases.
However, the fracture happened in costal cartilage will not cause the serious consequence to our health. Thus, rib fracture study with various restraint system loadings can provide useful information to the study of thoracic injury protection efficiency. Based on the sled experiments, the influence of impact speed and seatbelt loadings on chest injures including chest deflections and rib fractures need to be deeply investigated.

A series of eight Post-Mortem Human Subjects (PMHS) full-size impact experiments are conducted by Shaw et al. (2009), which contributed to the way of the frontal impact biomechanics research. These experiments can provide valuable data to biomechanics study, and serve as a basis for the validation of biomechanical Finite Element (FE) model (Crandall et al. 2011). Meanwhile, these experimental results demonstrate that it is difficult to find

${ }^{*}$ Corresponding author. E-mail: xiaosen@hnu.edu.cn 
the correlation between amount of chest injuries (like deflections and rib fractures) and the mechanical properties (Shaw et al. 2009). However, the position of the seatbelt and impact speed may have influences on the chest injury.

Compared with PMHS experiments, the technique of computational method allows for fast and accurate response while reproducing experimental results (Poulard et al. 2014). With the quick updating of high-performance computers and software calculation algorithms, FE method based on computer-aided characteristics has played an increasingly significant role in occupant safety studies. Furthermore, using frontal biomechanical Human Body Model (HBM) to perform chest injury research under collision conditions has been an applicable and advantageous approach. Among these studies, Poulard et al. (2015) analyses different chest injuries caused by different spine curves or morphology using the HBM based on the frontal impact experiments. Wang et al. (2016a, 2016b) uses a self-developed FE chest model to study the various criteria in rib fracture and the stress/strain associated chest injuries under different impact conditions. Hu et al. (2015) examines the passenger chest injuries in a collision by virtual experiment method and concludes that chest is the most serious injured segment among road crash injuries. Cai et al. (2013) introduces a new chest FE model based on the Chinese figures for road crash study. With the development of biomechanical HBM and biological material, these HBMs become more sophisticated, and can well reflect the human response during the collision.

Most of the current injury indexes are the macro figures obtained from experiments. The widely used one is the chest deflection, which is indicative of the risk of chest injuries such as living space of the chest internal organs. This indicator has been introduced to New Car Assessment Program (NCAP). However, the macro indicator is produced and calculated by the response of mechanical dummy. However, it cannot effectively reflect the stress/ strain response under various loading conditions as well as the injuries of soft tissues. Analysis of stress and strain in ribcage can reflect the mechanism of chest injury during the impact and provide the reference for improving protection efficiency of the seatbelt. Experimentally, it is difficult to place many sensors for study of the injury mechanism in detail. Therefore, coupling the experiment with the computational method is particularly meaningful for the study of occupant chest injury.

Previous studies have addressed the influence of seatbelt restraint systems using a strain-based probabilistic forecasting method (Forman et al. 2012) on the chest injury. Results have concluded that the seatbelt positional parameters contribute to the chest injury outcomes. However, in those cases the severe chest injury could be observed at the impact speed of $40 \mathrm{~km} / \mathrm{h}$ for a frontal sled impact. As a comparison, all the experimental data demonstrated high risk of rib fracture (2 more fractured ribs were observed in all of the sled tests). The accurate quantitative prediction of the rib fractures cannot be distinguished in frontal sled test at $40 \mathrm{~km} / \mathrm{h}$, which lead to difficulty in identifying the difference between simulation results (Xiao et al. 2017). Therefore, sensitivity studies under various impact speeds with the same seatbelt can give a better understanding of the results. Thus, the method for chest injury can show a new way on analysis of the injury mechanism. probabilistic prediction.

This study intends to investigate the influence of the impact speed on the chest deflections and chest injury risks. The model was created according to the whole-body sled frontal impact by utilizing a verified FE HBM. A full factor Design Of Experiments (DOE) was then established with factors of the seatbelt position, the seatbelt angle and the impact speed.

\section{Methods and materials}

A DOE was established to test the influence of the seatbelt position parameters and impact speed on chest injury outcomes (Figure 1). The parameters and the range of the factors were determined based on the sled test data. A parameter analysis was carried out by using a new HBM (Gayzik et al. 2011).

\subsection{Reference test}

A regular seatbelt restraint PMHS was positioned on the test sled. Eight male PMHSs, which were similar to the 50th percentile stature (in the US) were used. The test sled was developed according to the widely used middle size vehicle in the US (Ford Taurus) and a deceleration pulse applied in the experiment was the same for all the PMHS tests, of which the deceleration pulse was corresponding to an impact speed of $40 \mathrm{~km} / \mathrm{h}$ (Shaw et al. 2009). The restraint system was the regular seatbelt from Narricut ${ }^{\mathrm{TM}}$ and the webbing characteristics were discretized and used in the seatbelt material property definition $(6 \ldots .8 \%$ elongation, $26.7 \mathrm{kN}$ minimum tensile strength). During this test, the kinematic traces were recorded by the Vicon ${ }^{\mathrm{TM}}$ kinematic motion capture system in six degrees of freedom. All the injury outcomes were captured by Computed Tomography (CT) scan and dissection. These tests were reported and analysed in aspects of chest maximum compression (Shaw et al. 2009), spine kinematics (Crandall et al. 2014), restraint/surface force (Ash et al. 2013) and 3D kinematic animation (Donlon et al. 2015). Another study based on these tests was published in terms of the influence of spine curves on chest injuries (Poulard et al. 2015).

The deflection measuring locations were selected according to the Test Device for Human Occupant Restraint (THOR) dummy. Two measuring points in upper chest were defined at the 4 th rib and $40 \mathrm{~mm}$ from the sternum vertical centerline (Figure 2), meanwhile, the upper left measuring point was located near the heart. Another two measuring points in lower chest were positioned at about $80 \mathrm{~mm}$ away from the sternum vertical centerline at the 8th rib. All chest deflections were calculated according to the local coordinate system at the 8th thoracic vertebra along the forward direction (Shaw et al. 2009). 


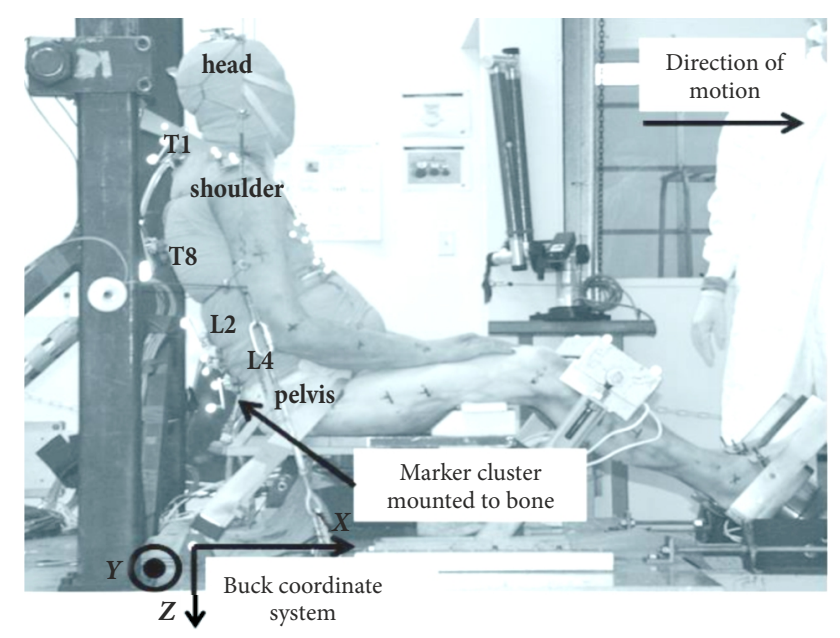

Figure 1. The whole view of the reference test with kinematical makers and coordinate system

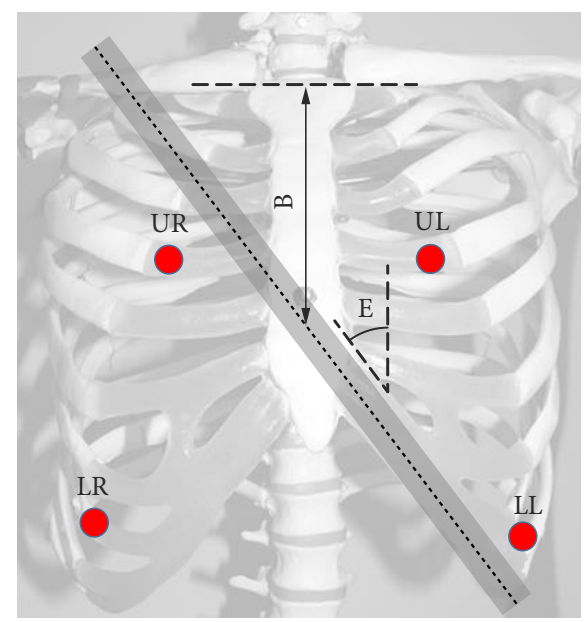

Figure 2. Diagram between measuring points and seatbelt position

\subsection{Belt FE model}

Global Human Body Models Consortium (GHBMC) version 4.2 was the 50th percentile male FE HBM. GHBMC model was then built upon experimental data. Derived from this model, a new generation of HBM were developed for biomechanical studies by research institutions with the support of automobile manufacturers. This HBM contains various types of elements and nodes (2197853 and 1259333, respectively). Moreover, GHBMC model had been verified (Gayzik et al. 2011) in segment level (like head and chest) and whole body level. The bio-fidelity of the chest was also validated in studies of wholebody level (Park et al. 2013, 2016) and rib segment level (Li et al. 2010a, 2010b). Among these verification studies, Park et al. $(2013,2016)$ did experimental verification for the biomechanical properties of the model in the passenger side under side impact conditions to improve this model so as to achieve better kinematics. In this study, contact algorithms mainly involved were automatic surface to surface contact between the human chest and seatbelt as well as automatic single surface or interior contact

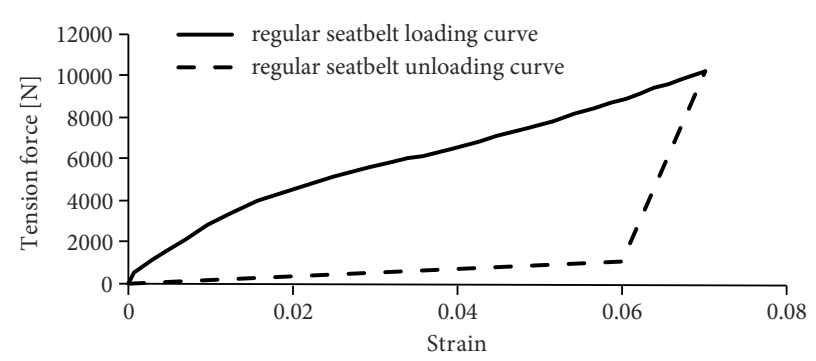

Figure 3. Seatbelt loading and unloading curves

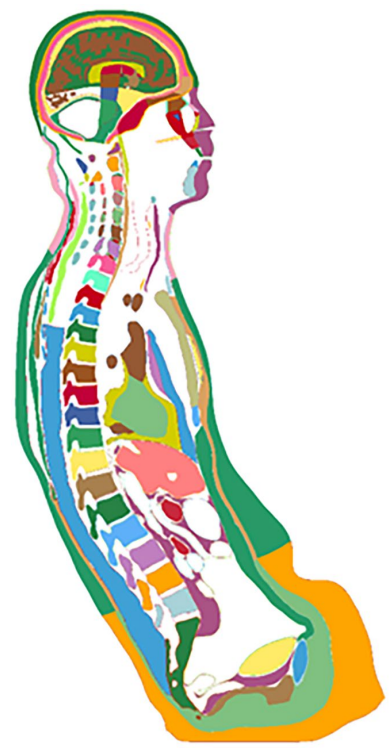

Figure 4. Sectional view of the chest

among the internal organs. The parameters of the seatbelt (loading and unloading curves) were simulated considering experimental data (Figure 3). The contact friction coefficient between the seatbelt and the HBM was set to 0.4 in order to keep the defined seatbelt path.

A reference to occupant torso anatomical structure included the spine, ribs, costal cartilage, sternum, clavicle, scapula, pelvis and internal organs (Figure 4). According to anatomy, a rib consists of the thin cortical bone and internal trabecular bone. As far as the FE model was concerned, the cortical bone was simulated by the shell element with the size of $3 \ldots 5 \mathrm{~mm}$. The hexahedral 8-node solid elements were used to simulate the medullary bone structure. These two types of bones were connected by sharing-nodes method in the FE model. Most of the internal organs and soft tissues were simulated by solid elements.

Biomaterial characteristics or parameters of the model were based on material biomechanics experiment. In this belted occupant model, bones were simulated based on elastic-plastic material, and soft tissue in chest and abdomen was characterized by properties of viscoelastic materials and super-elastic material model (Table 1). The default settings of rib failure strains in cortical bone was 0.018 (Kemper et al. 2007) and in trabecular bone was 0.13 (Kent et al. 2005). The heart was represented by the 
${ }^{\star}$ MAT_HEART_TISSUE as described in Equation (1), wherein $C, B_{1}, B_{2}, B_{3}$ were diastolic material coefficient, $E$ was the Lagrange-Green strains and $J$ was the Jacobian of the deformation gradient tensor. The lung was represented by the ${ }^{*}$ MAT_LUNG_TISSUE as described in Equation (2), wherein $C, \Delta, \alpha, \beta, C_{1}, C_{2}$ were material coefficient and $I$ was invariants of the Green strain.

$$
\begin{aligned}
& W(E, J)=\frac{C}{2} \cdot\left(e^{Q}-1\right)+W_{H}(J), \\
& Q=B_{1} \cdot E_{11}^{2}+B_{2} \cdot\left(E_{22}^{2}+E_{33}^{2}+E_{23}^{2}+E_{32}^{2}\right)+ \\
& B_{3} \cdot\left(E_{12}^{2}+E_{21}^{2}+E_{13}^{2}+E_{31}^{2}\right) ; \\
& W\left(I_{1}, I_{2}\right)=\frac{C}{2 \cdot \Delta} e^{\left(\alpha \cdot I_{2}^{2}+\beta \cdot I_{2}\right)}+ \\
& \frac{12 \cdot C_{1}}{\Delta \cdot\left(1-C_{2}\right)} \cdot\left(A^{\left(1+C_{2}\right)}-1\right) \\
& A^{2}=\frac{4}{3} \cdot\left(I_{1}+I_{2}\right)-1 .
\end{aligned}
$$

Meshing was conducted based on clinical Magnetic Resonance Imaging (MRI) and CT scans of organs and bones external geometries. According to the literatures, the thickness of rib cortical map to the ribs surface was $0.7 \ldots 1.2 \mathrm{~mm}$ with respect to the position of ribs (Wang et al. 2014; Choi, Lee 2009). Moreover, the clavicle cortical thickness was $1.7 \mathrm{~mm}$ (Andermahr et al. 2007; Duprey et al. 2010). Furthermore, the thickness of sternum cortical bone was set to $2.0 \mathrm{~mm}$ (Ito et al. 2009).
Chest injury mechanism was developed according to the rib bending test, which referred to criteria based on the strain, stress and a combination thereof. The ultimate strain was necessary in the calculation of the probabilistic prediction method based on strain analysis considering the age or injury level (Forman et al. 2012). Therefore, element elimination was not required in this new probabilistic method. Previous studies had shown that the model without element elimination functionality can also accurately predict the kinematic response and chest deflections (Motozawa et al. 2015; Xiao et al. 2015).

\subsection{Simulation matrix}

In the present study, GHBMC was utilized in frontal car crash according to the frontal test regulations - like Federal Motor Vehicle Safety Standard (FMVSS) 208 (Hollowell et al. 1998). Injury sensitivity analysis of the FE model was also introduced to predict the risks of fractures under different shoulder seatbelt loadings, defined by the seatbelt position, the seatbelt angle and the impact speeds (Table 2). The simulation of this study was established according to the configuration of the reference tests. The belted occupant model under sled test condition had been validated (Xiao et al. 2017) via the comparison of the kinematic traces, seatbelt forces and chest deflections between refer-

\begin{tabular}{|c|c|c|c|c|c|c|}
\hline & Material model & $\begin{array}{l}\text { Density } \\
{\left[\mathrm{g} / \mathrm{cm}^{3}\right]}\end{array}$ & $\begin{array}{l}\text { Young's } \\
\text { modulus [GPa] }\end{array}$ & $\begin{array}{l}\text { Poison's } \\
\text { ratio }\end{array}$ & $\begin{array}{l}\text { Yield stress } \\
{[\mathrm{MPa}]}\end{array}$ & \begin{tabular}{|c} 
Tangent modulus \\
{$[\mathrm{GPa}]$}
\end{tabular} \\
\hline $\begin{array}{l}\text { Rib cortical } \\
\text { (Li et al. 2010a; Iwamoto et al. 2002) }\end{array}$ & $\begin{array}{l}\text { elastic-plastic } \\
\text { rate dependent }\end{array}$ & 2 & 11.5 & 0.3 & 88 & 2.3 \\
\hline $\begin{array}{l}\text { Rib trabecular } \\
\text { (Li et al. 2010a; Zhao, Narwani 2005) }\end{array}$ & $\begin{array}{l}\text { elastic-plastic } \\
\text { rate dependent }\end{array}$ & 1 & 0.04 & 0.45 & 2.2 & 0.001 \\
\hline $\begin{array}{l}\text { Sternum cortical } \\
\text { (Iwamoto et al. 2002) }\end{array}$ & $\begin{array}{l}\text { elastic-plastic } \\
\text { rate dependent }\end{array}$ & 2 & 10.18 & 0.3 & 65.3 & 2.3 \\
\hline $\begin{array}{l}\text { Sternum trabecular } \\
\text { (Li et al. 2010a; Zhao, Narwani 2005) }\end{array}$ & $\begin{array}{l}\text { elastic-plastic } \\
\text { rate dependent }\end{array}$ & 1 & 0.04 & 0.45 & 2.2 & 0.001 \\
\hline $\begin{array}{l}\text { Costal cartilage } \\
\text { (Forman et al. 2010) }\end{array}$ & elastic & 1 & 0.05 & 0.4 & - & - \\
\hline $\begin{array}{l}\text { Vertebrae } \\
\text { (Zhao, Narwani 2005) }\end{array}$ & rigid & 2 & 0.354 & 0.3 & - & - \\
\hline $\begin{array}{l}\text { Clavicle cortical } \\
\text { (Astier et al. 2008) }\end{array}$ & $\begin{array}{l}\text { elastic-plastic } \\
\text { rate dependent }\end{array}$ & 2 & 9 & 0.3 & 80 & 0.9 \\
\hline $\begin{array}{l}\text { Clavicle trabecular } \\
\text { (Astier et al. 2008) }\end{array}$ & $\begin{array}{l}\text { elastic-plastic } \\
\text { rate dependent }\end{array}$ & 1 & 0.5 & 0.4 & 18 & 0.01 \\
\hline $\begin{array}{l}\text { Intervertebral disc } \\
\text { (Zhao, Narwani 2005) }\end{array}$ & Elastic & 1 & 0.005 & 0.4 & - & - \\
\hline $\begin{array}{l}\text { Heart } \\
\text { (Deng et al. 1999) }\end{array}$ & hyper elastic & 1 & \multicolumn{4}{|c|}{$C=1.085 \mathrm{kPa}, B_{1}=24.26, B_{2}=40.52, B_{3}=1.63,{ }^{*} P=2.4825 \mathrm{GPa}$} \\
\hline $\begin{array}{l}\text { Lung } \\
\text { (Yuen 2009) }\end{array}$ & $\begin{array}{l}\text { transversely } \\
\text { anisotropic }\end{array}$ & 0.288 & \multicolumn{4}{|c|}{$\begin{array}{l}{ }^{* *} K=2.66 \mathrm{MPa}, \Delta=0.1 \mathrm{~mm}, C=1.115 \cdot 10^{-3} \mathrm{MPa} \\
\alpha=0.213, \beta=-0.343, C_{1}=1.002 \cdot 10^{-3} \mathrm{MPa}, C_{2}=2.04\end{array}$} \\
\hline
\end{tabular}
ence tests and simulations. Different deceleration pulses scaled from the test deceleration pulse were introduced to represent the impact speeds of 20 and $30 \mathrm{~km} / \mathrm{h}$ to investigate the influence of the impact speeds on the chest injury

Table 1. Material parameters of the bones and main organs in the chest

Notes: ${ }^{*} \mathrm{P}$ is pressure in the muscle tissue; ${ }^{* *} \mathrm{~K}$ is bulk modulus. 
Table 2. Definition of the levels of three factors

\begin{tabular}{|c|l|c|c|}
\hline Level & Belt position & Belt angle $\left[^{\circ}\right]$ & Sled speed $[\mathrm{km} / \mathrm{h}]$ \\
\hline 1 & top-sternum & 40 & 20 \\
\hline 2 & mid-sternum & 50 & 30 \\
\hline 3 & bottom-sternum & 60 & 40 \\
\hline
\end{tabular}

outcomes. The variable of shoulder seatbelt path was defined from the shoulder seatbelt centerline position. Other seatbelt paths correspond to the variability observed in the experiments in terms of seatbelt position and seatbelt angle. The route used to define the lap seatbelt were kept at the same location during this study.

A full factor DOE study, which consisted of twentyseven simulations was performed based on the mentioned belted occupant model. All the establishments were finished according to the test environment. All simulations were performed with LS-DYNA Massively Parallel Processing (MPP) in the mode of dynamic FE solver (version 970, Livermore Software Technology Corporation, Livermore, CA, US). In the continuous study, the simulation ID was defined using the combination of characters and numbers. The B meant the seatbelt position and the E meant the seatbelt angle (Figure 2). And the numbers followed these characters were the corresponding levels of these factors. The impact speed was shown at last. For example, B2E2(40) referred to a simulation in which the seatbelt position was in level 2, the seatbelt angle was in level 2 and the test impact speed was at $40 \mathrm{~km} / \mathrm{h}$.

\section{Results}

Two indexes of the rib fracture risk and the chest deflection were used as the judgments to evaluate the injury of chest caused by the parameters: the impact speed, the seatbelt angle and the seatbelt position.

\subsection{Chest deflection}

The four measuring points were located at Upper Right (UR), Upper Left (UL), Lower Right (LR) and Lower Left (LL) (Figure 2).

Impact speed played an important role in the peak chest deflection study. As the impact speed increased, both of the amount of chest compressions and extensions would increase with the exception of one special measuring location, which was shown in UR measuring point (Figure 5). The deflection increase of UR measuring point was not obvious (about $3 \mathrm{~mm}$ ) between results from impact speed at 30 and $40 \mathrm{~km} / \mathrm{h}$. Nevertheless, their increase rates were not the same. For example, changes in the UL and LL were both more than $20 \mathrm{~mm}$, and the change in UR was less than $15 \mathrm{~mm}$. In addition, the extent of changes in the left ribcage measuring points were larger (more than $20 \mathrm{~mm}$ in the left) than that in the right ribcage (less than $15 \mathrm{~mm}$ in the right), especially for the simulation with a low seatbelt position and a large seatbelt angle. The chest deflections would increase with the increase of seatbelt angle under the three study impact speeds. Variations of chest deflections at four measuring points were all of significance, the $p$-values of which were lower than 0.05 .

However, judging from the numerical analysis (amplitude), the left side of the chest increased more than the right one. The amounts of peak deflection variation with the change of seatbelt angle were all in the same changing direction. This means the peak deflection would increase in upper two points and decrease in lower two points with the increase of the seatbelt angle. There was no obvious influence of impact speeds on the difference of deflection amplitude cause by the variation of seatbelt angle. The changes of four measuring points were different in direction and amplitude. Specifically, some of the deflections would increase with the increase of seatbelt angle (LL), meanwhile, some of the deflections would decrease (UL) during this process (Figure 5).
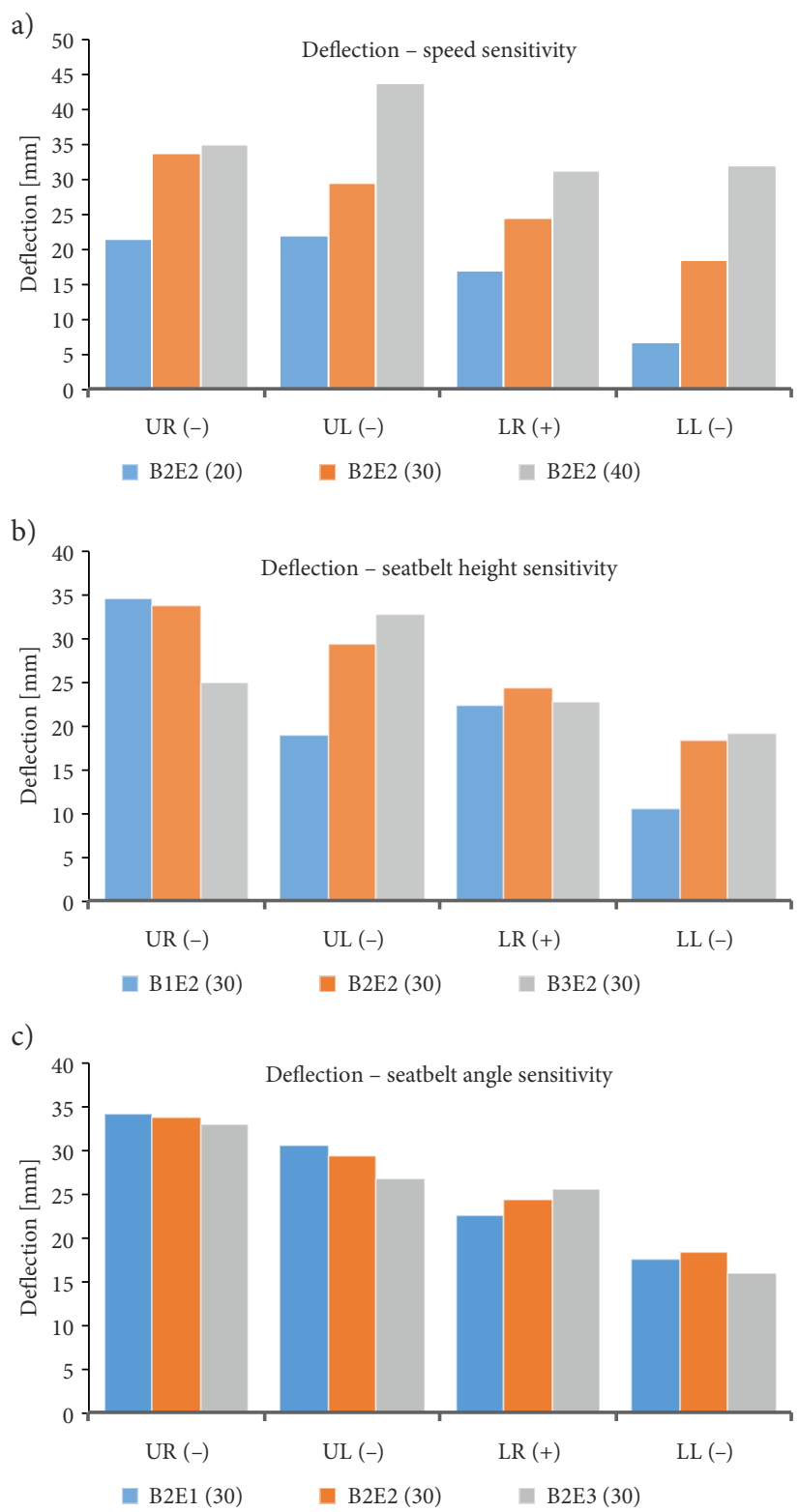

Figure 5. Peak chest deflection sensitivity with study parameters of impact speed (a), seatbelt position (b) and seatbelt angle (c): “+”- extension; “-” - compression 
The changes resulting from the influence of impact speeds at all the four measuring points $(15 \ldots 25 \mathrm{~mm})$ were more significant compared with those resulting from seatbelt parameters (most of them less than $10 \mathrm{~mm}$ ) judging from the peak deflections. Specifically, the amount of deflections in the left side varied more, which was up to more than $20 \mathrm{~mm}$ compared with those in the right side.

\subsection{Rib fracture results}

The maximum strain was calculated in accordance with the probabilistic prediction method (Forman et al. 2012) based on the post processing. Besides seatbelt position parameters and impact speed, injury level (number of fractured ribs) and age were also considered in the fracture risk calculation. The age used in this study was 55 , which was the average age of the 8 test subjects in the reference test and represented the age of old people. Fractured ribs appeared in almost all simulation cases (25 out of 27 simulations). With the increase of the fractured ribs, the injury risks would decrease (Table 3 ). The results were divided into four different groups in different colours to represent the ribcage fracture risk of low, medium, serious and high. The difference between each group was $25 \%$.
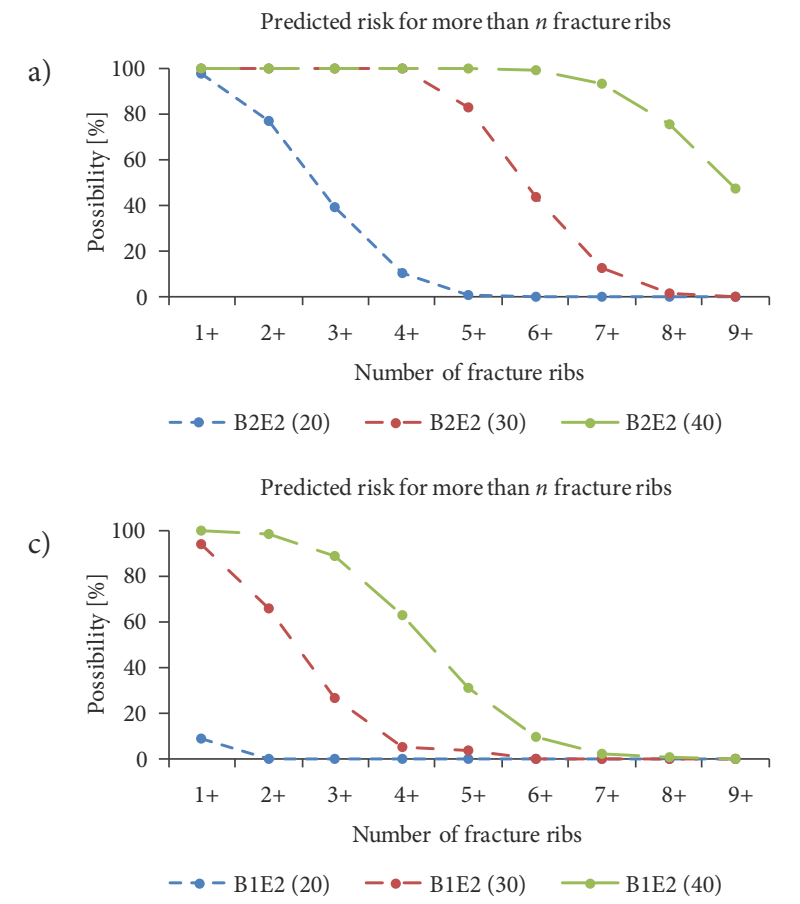

Predicted risk for more than $n$ fracture ribs

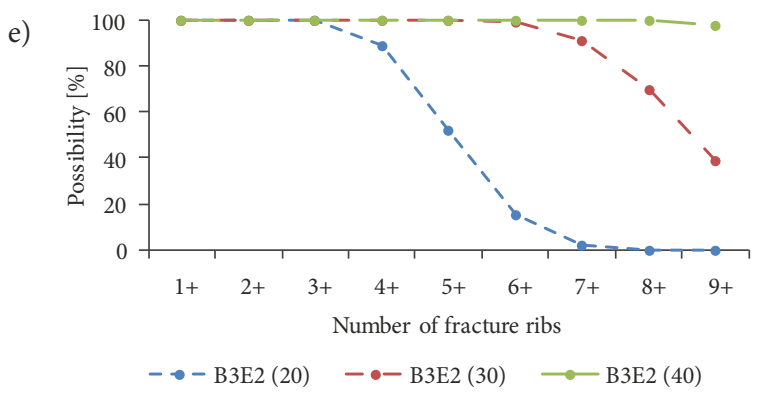

If the seatbelt position changed from top-sternum to middle-sternum, the injury risks would increase. Meanwhile, when the seatbelt position changed from middlesternum to bottom-sternum, the injury risks would increase too.

The injury risks would decrease with the decrease of the seatbelt position at a small seatbelt angle. In addition, the exception was that the injury risks would increase with the decrease of the seatbelt position at other two specific seatbelt angles.

Impact speed had a dominant influence on the chest injury risks (Figure 6) judging from the injury prediction results. Especially for the lower impact speed, the fracture risk decreased significantly (most of the results were lower than 50\%). With the increase of impact speed, the probability of fracture would increase accordingly, and the rate of change in each section was basically identical. Among these results, there were rarely serious chest injuries (mostly happened in seatbelt position level 3 for less than 4 more fractured ribs), and most of the predicted injury levels were less than two fractured ribs at the impact speed of $20 \mathrm{~km} / \mathrm{h}$. When the impact speed increased to $30 \mathrm{~km} / \mathrm{h}$, the number of resulting fractured ribs would

b)

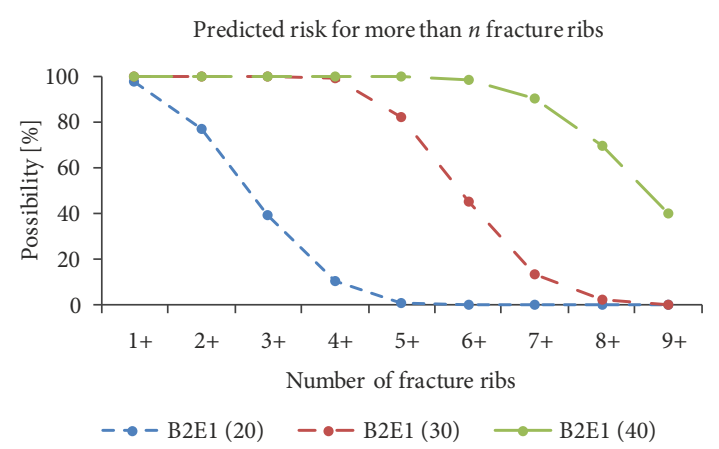

d)

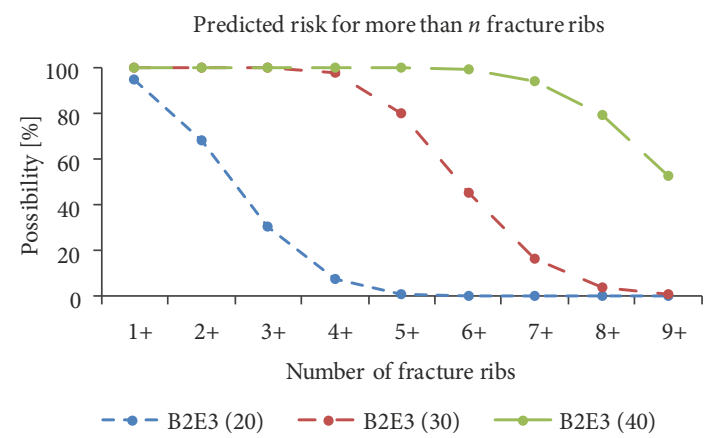

Figure 6. The influence of impact speed on chest injury (number of fractured ribs) 
reach 3 more and even 5 more fractures in some cases for high injury risks (higher than 75\%). Thus, all the cases under this impact speed were generally classified as serious injury risks, which was rating as Abbreviated Injury Scale (AIS) $3+$. When collision speed increased to $40 \mathrm{~km} / \mathrm{h}, 5$ more fractured ribs would appear in all individual case, which was a serious situation in the event of a pure seatbelt restraint frontal collision. All these cases with impact speed of $30 \mathrm{~km} / \mathrm{h}$ and $40 \mathrm{~km} / \mathrm{h}$ should be paid special attention.

The impact speed had a dominant influence on chest injury outcomes. The influence of seatbelt on the chest injury was identical for different particular speeds. Specifically, the fracture risk was greatly affected by seatbelt position, while also obviously though little slightly effected by seatbelt angle. In particular, with the increase of the seatbelt

Impact speed-rib fracture sensitivity (right side)

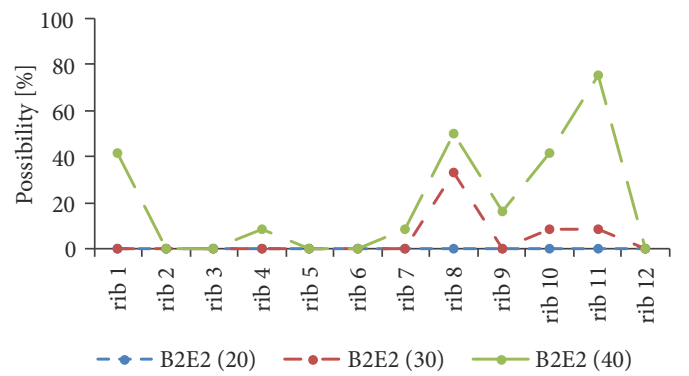

position, the ribcage injury risk would rise obviously (more than $25 \%$ increase). The fracture risk is negatively correlated with seatbelt angle, which meant the ribcage injury risks would increase while the seatbelt position changed from top-sternum to bottom-sternum. However, when the seatbelt was 40 degrees, the changing trend will reverse, which meant when the seatbelt became lower the injury risks would decrease (changed from B1E1 to B1E3). The changing trends of the fracture risk of each rib (Figure 7) can match the changing direction of the Table 3 . The lower ribcage ribs would be greatly influenced (more than 25\%) by the impact speed, due to the directly loading from the seatbelt. The upper ribcage especially from rib 2 to rib 5 in both sides were seldom or slightly influenced (less than $10 \%$ ) by the variation of seatbelt loading and impact speed.

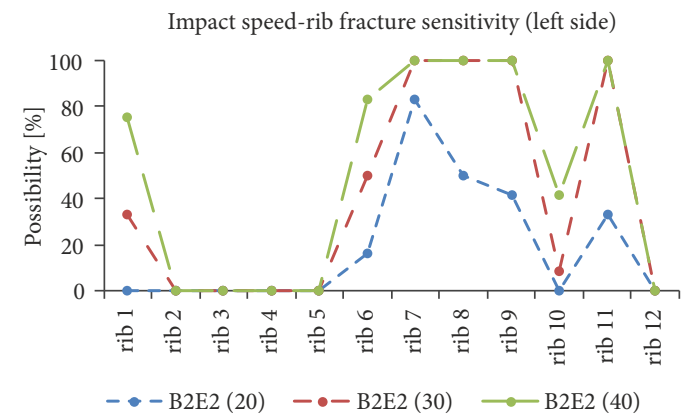

Figure 7. Influence of impact speed on fracture risk results of each rib

Table 3. Predict risks of certain number of fractured ribs

\begin{tabular}{|c|c|c|c|c|c|c|c|c|c|}
\hline \multirow{2}{*}{ Simulation ID } & \multicolumn{9}{|c|}{ Predicted risk for more than $n$ fracture ribs } \\
\hline & $1+$ & $2+$ & $3+$ & $4+$ & $5+$ & $6+$ & $7+$ & $8+$ & $9+$ \\
\hline B1E1(20) & $38.89 \%$ & $2.78 \%$ & $0.0 \%$ & $0.0 \%$ & $0.0 \%$ & $0.0 \%$ & $0.0 \%$ & $0.0 \%$ & $0.0 \%$ \\
\hline B1E2(20) & $8.33 \%$ & $0.0 \%$ & $0.0 \%$ & $0.0 \%$ & $0.0 \%$ & $0.0 \%$ & $0.0 \%$ & $0.0 \%$ & $0.0 \%$ \\
\hline B1E3(20) & $0.0 \%$ & $0.0 \%$ & $0.0 \%$ & $0.0 \%$ & $0.0 \%$ & $0.0 \%$ & $0.0 \%$ & $0.0 \%$ & $0.0 \%$ \\
\hline B2E1(20) & $97.30 \%$ & $77.28 \%$ & $39.24 \%$ & $10.22 \%$ & $0.96 \%$ & $0.0 \%$ & $0.0 \%$ & $0.0 \%$ & $0.0 \%$ \\
\hline B2E2(20) & $97.30 \%$ & $77.28 \%$ & $39.24 \%$ & $10.22 \%$ & $0.96 \%$ & $0.0 \%$ & $0.0 \%$ & $0.0 \%$ & $0.0 \%$ \\
\hline B2E3(20) & $94.60 \%$ & $68.06 \%$ & $29.98 \%$ & $6.79 \%$ & $0.58 \%$ & $0.0 \%$ & $0.0 \%$ & $0.0 \%$ & $0.0 \%$ \\
\hline B3E1(20) & $100.0 \%$ & $100.0 \%$ & $100.0 \%$ & $88.86 \%$ & $51.67 \%$ & $15.6 \%$ & $2.11 \%$ & $0.0 \%$ & $0.0 \%$ \\
\hline B3E2(20) & $100.0 \%$ & $100.0 \%$ & $100.0 \%$ & $89.11 \%$ & $52.12 \%$ & $15.32 \%$ & $1.73 \%$ & $0.0 \%$ & $0.0 \%$ \\
\hline B3E3(20) & $100.0 \%$ & $100.0 \%$ & $100.0 \%$ & $97.69 \%$ & $80.32 \%$ & $45.64 \%$ & $15.34 \%$ & $2.55 \%$ & $0.0 \%$ \\
\hline B1E1(30) & $100.0 \%$ & $91.34 \%$ & $59.11 \%$ & $21.13 \%$ & $3.26 \%$ & $0.16 \%$ & $0.0 \%$ & $0.0 \%$ & $0.0 \%$ \\
\hline B1E2(30) & $94.09 \%$ & $65.57 \%$ & $26.53 \%$ & $5.11 \%$ & $3.6 \%$ & $0.0 \%$ & $0.0 \%$ & $0.0 \%$ & $0.0 \%$ \\
\hline B1E3(30) & $73.26 \%$ & $29.46 \%$ & $5.32 \%$ & $0.29 \%$ & $0.0 \%$ & $0.0 \%$ & $0.0 \%$ & $0.0 \%$ & $0.0 \%$ \\
\hline B2E1(30) & $100.0 \%$ & $100.0 \%$ & $100.0 \%$ & $98.75 \%$ & $81.92 \%$ & $45.03 \%$ & $13.77 \%$ & $2.05 \%$ & $0.0 \%$ \\
\hline B2E2(30) & $100.0 \%$ & $100.0 \%$ & $100.0 \%$ & $100.0 \%$ & $82.88 \%$ & $43.98 \%$ & $12.82 \%$ & $1.85 \%$ & $0.0 \%$ \\
\hline B2E3(30) & $100.0 \%$ & $100.0 \%$ & $100.0 \%$ & $97.57 \%$ & $79.61 \%$ & $45.10 \%$ & $15.80 \%$ & $3.20 \%$ & $0.36 \%$ \\
\hline B3E1(30) & $100.0 \%$ & $100.0 \%$ & $100.0 \%$ & $100.0 \%$ & $99.75 \%$ & $96.82 \%$ & $84.26 \%$ & $57.66 \%$ & $27.22 \%$ \\
\hline B3E2(30) & $100.0 \%$ & $100.0 \%$ & $100.0 \%$ & $100.0 \%$ & $100.0 \%$ & $99.01 \%$ & $91.55 \%$ & $70.13 \%$ & $38.96 \%$ \\
\hline B3E3(30) & $100.0 \%$ & $100.0 \%$ & $100.0 \%$ & $100.0 \%$ & $100.0 \%$ & $99.90 \%$ & $98.59 \%$ & $91.54 \%$ & $72.22 \%$ \\
\hline B1E1(40) & $100.0 \%$ & $100.0 \%$ & $98.92 \%$ & $89.11 \%$ & $61.08 \%$ & $26.81 \%$ & $6.6 \%$ & $0.79 \%$ & $0.0 \%$ \\
\hline B1E2(40) & $100.0 \%$ & $98.51 \%$ & $88.32 \%$ & $62.65 \%$ & $30.86 \%$ & $9.53 \%$ & $1.66 \%$ & $0.14 \%$ & $0.0 \%$ \\
\hline B1E3(40) & $97.68 \%$ & $83.2 \%$ & $51.82 \%$ & $20.48 \%$ & $4.61 \%$ & $0.52 \%$ & $0.02 \%$ & $0.0 \%$ & $0.0 \%$ \\
\hline B2E1(40) & $100.0 \%$ & $100.0 \%$ & $100.0 \%$ & $100.0 \%$ & $99.88 \%$ & $98.34 \%$ & $90.41 \%$ & $69.77 \%$ & $39.86 \%$ \\
\hline B2E2(40) & $100.0 \%$ & $100.0 \%$ & $100.0 \%$ & $100.0 \%$ & $99.93 \%$ & $98.88 \%$ & $92.89 \%$ & $75.52 \%$ & $47.32 \%$ \\
\hline B2E3(40) & $100.0 \%$ & $100.0 \%$ & $100.0 \%$ & $100.0 \%$ & $99.94 \%$ & $99.11 \%$ & $94.16 \%$ & $78.97 \%$ & $52.41 \%$ \\
\hline B3E1(40) & $100.0 \%$ & $100.0 \%$ & $100.0 \%$ & $100.0 \%$ & $100.0 \%$ & $100.0 \%$ & $99.99 \%$ & $99.71 \%$ & $97.38 \%$ \\
\hline B3E2(40) & $100.0 \%$ & $100.0 \%$ & $100.0 \%$ & $100.0 \%$ & $100.0 \%$ & $100.0 \%$ & $99.99 \%$ & $99.76 \%$ & $97.64 \%$ \\
\hline B3E3(40) & $100.0 \%$ & $100.0 \%$ & $100.0 \%$ & $100.0 \%$ & $100.0 \%$ & $100.0 \%$ & $100.0 \%$ & $100 \%$ & $99.97 \%$ \\
\hline
\end{tabular}




\section{Discussion}

\subsection{Study method and HBM}

Rib fractures rarely occur at the 10th ribs in both sides of the ribcage in the road accidents, but likely to occur in current simulation study. The underlying cause should be the different ribcage shapes. Different shapes of human chest will cause different contact areas between seatbelt and chest (Kent et al. 2005). In particular, chest subsidence will vary among different ages and peoples. This will also lead to different injury outcomes of the ribcage. In this case, the injury risks of ribcage or each rib will be different. In particular, CT reconstructed lateral view of the thoracic cage illustrating age-related change in the rib slope according to Kent et al. (2005).

Fractures also rarely occur in the first ribs due to the protection of clavicle. However, in the present study, great stress/strain concentration area often appeared near the joints between ribs and costal cartilage. Meanwhile, fractures of sternum and costal cartilage are common in the experiments (Shaw et al. 2009), but hard to detect in the simulation. There exists a need to address these issues in the future.

\subsection{Effect of material model application}

Application of soft tissue biomaterials in constitutive model will have a critical impact on the final result of chest injury (Murakami et al. 2006). In this study, we selected material constitutive model among certain conditions can improve the accuracy of injury results, because the compressive load imposed to the bone structure as well as soft tissue structures generated by seatbelt tension loads. Soft tissue materials in the HBM are defined by using superelastic and visco-elastic models, which are well developed biological material models in LS-DYNA. These material models can well represent collision responses of a biomechanical material.

\subsection{Chest deflection}

A high impact speed can provide a large kinematical energy. Thus, inertia has a very large influence on chest torsional. Specifically, different amount of inertia will lead to different chest injury outcomes (Xiao et al. 2017). Therefore, reducing ribcage fractures by means of limiting the rotation of the chest should be effective. Chest deflection is associated with the position of the seatbelt. Meanwhile, it is also related to the seatbelt contact area. But at this stage, with a certain seatbelt, other ways like increasing the contact area may be a possible way to reduce the chest deflections. The results indicate that the chest injury is influenced by the seatbelt position. Therefore, the occupant should be restrained in a right seatbelt position (Xiao et al. 2017).

However, trends of the chest deflections of the upper two and the lower two measuring points in the speed sensitivity study are consistent (they do not change in the same direction with the change of impact speed), which may result from the ribcage stiffness reduction caused by influence of VICON markers, which are rigid metal markers (Shaw et al. 2009).

\subsection{Rib fracture risk}

The influence of impact speeds on rib fracture risk is much more than the influence of seatbelt parameters. Risks of rib fracture numbers will increase with the increase of impact speed. This due to the energy of the impact is linear correlation to the square terms of impact speed. Results of rib fracture suggested that a seatbelt angle of 40 degrees with the seatbelt at top-sternum would result in a small injury risk of the whole ribcage compared with other seatbelt loading conditions.

According to the analysis on influence of impact speed and seatbelt position parameters on ribcage strain analysis (fracture risks), the fracture risks of the 6th to 10th ribs are high in all simulation cases, especially ribs on the left ribcage. This is also observed when other boundary conditions are used (Xiao et al. 2015). The reason is there are no other bones protection in the lower torso except ribs, which means nearly all the seatbelt loading will directly be applied on these ribs. As a comparison, the clavicle will uphold most of the seatbelt load in the upper torso.

\subsection{Relationship between fracture risk and deflection}

The influences of impact speed on rib fracture risks and chest deflections are similar, which indicates that there are some links between these two chest injury indexes (Kent et al. 2005). According to the test (Shaw et al. 2009), the seatbelt is positioned with the reference to a middle point of sternum. The seatbelt angle in the sled tests is about 50 degrees relative to the vertical centerline of the sternum. Research on rib fracture risk summarized that the ribcage had relatively higher crash resistance under the condition of high seatbelt position (top-sternum), small seatbelt angle and low impact speed. While four-point chest deflection study shows that the peak deflection would be small under the condition of high seatbelt position, small seatbelt angle and small impact speed.

Injury risks and chest deflections are two different descriptions of the chest injury. However, there are also some differences between them. The fracture risk is associated with the area of the contact surface, while the chest deflection is associated with the twist of the ribcage. In particular, increasing the contact area (like reduce seatbelt angle) will lead to lower rib fracture risk, and reducing the twist (like high seatbelt position) will lead to smaller chest deflections. Contact area and twist will also affect both deflections and injury risks depending on which factor is the superior. This shows that there were differences and associations between the rib fracture risks and chest deflections. Chest deflection is a macro index, which is widely used to evaluate the chest injury. It can 
reflect (Kent et al. 2005) the injury severity of the ribcage. The deflections cannot give us more detailed information about the chest injury, compared with the strain analysis, which was carried out to better understand the mechanism of chest injury with rib fractures. In addition, the strain and stress is more accurate to reflect the potential risk of the rib fractures.

\section{Conclusions}

In order to improve the protection efficiency of the seatbelt restraint system, the seatbelt influence on chest injury under different impact speeds is investigated using a verified belted HBM in terms of the influence of impact speed on the chest deflection and fracture outcomes. The conclusions can be drawn as follows based on the results:

- the impact speed has a significant influence on the chest injury risk. Meanwhile, the correlation between seatbelt loadings and injury response is of nonlinear feature. Besides, the influence of the different seatbelt loadings caused by seatbelt position parameters;

- the ribcage fracture risk is determined based on a strain analysis to reflect the change of injury mechanism caused by the impact speed, which predicts the potential injury outcomes of the chest;

- four-point chest deflections reflect the more detailed compression at four locations caused by the seatbelt loading rather than the maximum deflection.

\section{Acknowledgements}

This study was conducted in Center for Applied Biomechanics in the University of Virginia (US) and supported by funds from China Scholarship Council (CSC), Natural Science Foundation of Hebei Province (E2020202017), National Natural Science Foundation of China (Grant No 51405150) and National Natural Science Foundation of China (Grant No 51475154).

\section{Funding}

This study was supported by funds from China Scholarship Council (CSC), Natural Science Foundation of Hebei Province (E2020202017), National Natural Science Foundation of China (Grant No 51405150) and National Natural Science Foundation of China (Grant No 51475154).

\section{Disclosure statement}

No competing financial, professional, or personal interests from other parties.

\section{References}

Andermahr, J.; Jubel, A.; Elsner, A.; Johann, J.; Prokop, A.; Rehm, K. E.; Koebke, J. 2007. Anatomy of the clavicle and the intramedullary nailing of midclavicular fractures, Clinical Anatomy 20(1): 48-56. https://doi.org/10.1002/ca.20269
Ash, J. H.; Shaw, G.; Lessley, D. J.; Crandall, J. 2013. PMHS restraint and support surface forces in simulated frontal crashes, International Journal of Automotive Engineering 4(2): 41-46. https://doi.org/10.20485/jsaeijae.4.2_41

Astier, V.; Thollon, L.; Arnoux, P. J.; Mouret, F.; Brunet, P. C. 2008. Development of a finite element model of the shoulder: application during a side impact, International Journal of Crashworthiness 13(3): 301-312. https://doi.org/10.1080/13588260801933741

Baker, S. P.; O’Neill, B.; Haddon, W.; Long, W. B. 1974. The injury severity score: a method for describing patients with multiple injuries and evaluating emergency care, The Journal of Trauma: Injury, Infection, and Critical Care 14(3): 187-196. https://doi.org/10.1097/00005373-197403000-00001

Cai, Z.-H.; Lan, F.-C.; Chen, J.-Q.; Liu, W.-G.; Lei, D. 2013. Development and validation for finite element model of human thorax based on automotive impact injuries, Journal of Medical Biomechanics (1): 36-43. (in Chinese).

Choi, H. Y.; Lee, I. 2009. Thorax FE model for older population, in Proceedings of Joint Symposium: Symposium on Sports Engineering, Symposium on Human Dynamics 2009: 367-372. https://doi.org/10.1299/jsmesports.2009.0_367

Crandall, J. R.; Bose, D.; Forman, J.; Untaroiu, C. D.; ArreguiDalmases, C.; Shaw, C. G.; Kerrigan, J. R. 2011. Human surrogates for injury biomechanics research, Clinical Anatomy 24(3): 362-371. https://doi.org/10.1002/ca.21152

Crandall, J.; Lessley, D.; Shaw, G.; Ash, J. 2014. Displacement response of the spine in restrained PMHS during frontal impacts, International Journal of Automotive Engineering 5(2): 59-64. https://doi.org/10.20485/jsaeijae.5.2_59

Deng, Y.; Kong, W.; Ho, H. 1999. Development of a finite element human thorax model for impact injury studies, SAE Technical Paper 1999-01-0715. https://doi.org/10.4271/1999-01-0715

Donlon, J. P.; Poulard, D.; Lessley, D.; Riley, P.; Subit, D. 2015. Understanding how pre-impact posture can affect injury outcome in side impact sled tests using a new tool for visualization of cadaver kinematics, Journal of Biomechanics 48(3): 529-533. https://doi.org/10.1016/j.jbiomech.2014.12.042

Duprey, S.; Subit, D.; Guillemot, H.; Kent, R. W. 2010. Biomechanical properties of the costovertebral joint, Medical Engineering \& Physics 32(2): 222-227. https://doi.org/10.1016/j.medengphy.2009.12.001

Forman, J. L.; Del Pozo de Dios, E.; Kent, R. W. 2010. A pseudoelastic effective material property representation of the costal cartilage for use in finite element models of the whole human body, Traffic Injury Prevention 11(6): 613-622. https://doi.org/10.1080/15389588.2010.517254

Forman, J. L.; Kent, R. W.; Mroz, K.; Pipkorn, B.; Bostrom, O.; Segui-Gomez, M. 2012. Predicting rib fracture risk with whole-body finite element models: development and preliminary evaluation of a probabilistic analytical framework, Annals of Advances in Automotive Medicine 56: 109-124.

Gayzik, F. S.; Moreno, D. P.; Vavalle, N. A.; Rhyne, A. C.; Stitzel, J. D. 2011. Development of the global human body models consortium midsized male full body model, in Injury Biomechanics Research: Proceedings of the Thirty-Ninth International Workshop, National Highway Traffic Safety Administration (NHTSA), Washington, DC, US, 1-11.

Hollowell, W. T.; Gabler, H. C.; Stucki, S. L.; Summers, S.; Hackney, J. R. 1998. Review of Potential Test Procedures for FMVSS No. 208. National Highway Traffic Safety Administration (NHTSA), Washington, DC, US. 110 p. Available from Internet: https://www.nhtsa.gov/sites/nhtsa.dot.gov/files/nprm_208_0. pdf 
Hu, Y.; Liang, Y.; Jiang, C.; Liu, X.; Liao, G.; Feng, Q.; Liu, W. 2015. Application of the occupant injury investigation in frontal crash based on THUMS model, Journal of Automotive Safety and Energy 6(4): 379-383. (in Chinese).

Ito, O.; Dokko, Y.; Ohashi, K. 2009. Development of adult and elderly FE thorax skeletal models, SAE Technical Paper 200901-0381. https://doi.org/10.4271/2009-01-0381

Iwamoto, M.; Kisanuki, Y.; Watanabe, I.; Furusu, K.; Miki, K.; Hasegawa, J. 2002. Development of a finite element model of the total human model for safety (THUMS) and application to injury reconstruction, in Proceedings of the International IRCOBI Conference, 18-20 September 2002, Munich, Germany, 1-12.

Kemper, A. R.; McNally, C.; Pullins, C. A.; Freeman, L. J.; Duma, S. M.; Rouhana, S. W. 2007. The biomechanics of human ribs: material and structural properties from dynamic tension and bending tests, SAE Technical Paper 2007-22-0011. https://doi.org/10.4271/2007-22-0011

Kent, R.; Lee, S.-H.; Darvish, K.; Wang, S.; Poster, C. S.; Lange, A. W.; Brede, C.; Lange, D.; Matsuoka, F. 2005. Structural and material changes in the aging thorax and their role in crash protection for older occupants, SAE Technical Paper 2005-22-0011. https://doi.org/10.4271/2005-22-0011

Kent, R.; Patrie, J. 2005. Chest deflection tolerance to blunt anterior loading is sensitive to age but not load distribution, Forensic Science International 149(2-3): 121-128. https://doi.org/10.1016/j.forsciint.2004.04.086

Li, Z.; Kindig, M. W.; Kerrigan, J. R.; Untaroiu, C.; Subit, D.; Crandall, J., Kent, R. W. 2010a. Rib fractures under anteriorposterior dynamic loads: Experimental and finite-element study, Journal of Biomechanics 43(2): 228-234.

https://doi.org/10.1016/j.jbiomech.2009.08.040

Li, Z.; Kindig, M. W.; Subit, D.; Kent, R. W. 2010b. Influence of Mesh Density, Cortical Thickness and Material Properties on Human Rib Fracture Prediction, Medical Engineering \& Physics 32(9): 998-1008.

https://doi.org/10.1016/j.medengphy.2010.06.015

Motozawa, Y.; Okamoto, M.; Mori, F. 2015. Comparison of whole body kinematics between fracture and non-fracture finite element human body models during side impact, in IRCOBI Conference Proceedings, 9-11 September 2015, Lyon, France, 634-647.

Murakami, D.; Kobayashi, S.; Torigaki, T.; Kent, R. 2006. Finite element analysis of hard and soft tissue contributions to thoracic response: sensitivity analysis of fluctuations in boundary conditions, SAE Technical Paper 2006-22-0008.

https://doi.org/10.4271/2006-22-0008

Nahum, A. M.; Melvin, J. W. 2002. Accidental Injury: Biomechanics and Prevention. Springer. $637 \mathrm{p}$. https://doi.org/10.1007/978-0-387-21787-1

Nirula, R.; Pintar, F. A. 2008. Identification of vehicle components associated with severe thoracic injury in motor vehicle crashes: a CIREN and NASS analysis, Accident Analysis \& Prevention 40(1): 137-141.

https://doi.org/10.1016/j.aap.2007.04.013

Park, G.; Kim, T.; Crandall, J. R.; Arregui-Dalmases, C.; LuzonNarro, J. 2013. Comparison of kinematics of GHBMC to PMHS on the side impact condition, in 2013 IRCOBI Conference Proceedings, 11-13 September 2013, Gothenburg, Sweden, 368-379.
Park, G.; Kim, T.; Panzer, M.B.; Crandall, J. R. 2016. Validation of shoulder response of human body finite-element model (GHBMC) under whole body lateral impact condition, $A n-$ nals of Biomedical Engineering 44(8): 2558-2576.

https://doi.org/10.1007/s10439-015-1546-6

Poulard, D.; Subit, D.; Donlon, J.-P.; Kent, R. W. 2015. Development of a computational framework to adjust the pre-impact spine posture of a whole-body model based on cadaver tests data, Journal of Biomechanics 48(4): 636-643. https://doi.org/10.1016/j.jbiomech.2014.12.050

Poulard, D.; Subit, D.; Donlon, J.-P.; Lessley, D. J.; Kim, T.; Park, G.; Kent, R. W. 2014. The contribution of pre-impact spine posture on human body model response in whole-body side impact, SAE Technical Paper 2014-22-0014. https://doi.org/10.4271/2014-22-0014

Ruan, J.; El-Jawahri, R.; Chai, L.; Barbat, S.; Prasad, P. 2003. Prediction and analysis of human thoracic impact responses and injuries in cadaver impacts using a full human body finite element model, SAE Technical Paper 2003-22-0014.

https://doi.org/10.4271/2003-22-0014

Shaw, G.; Parent, D.; Purtsezov, S.; Lessley, D.; Crandall, J.; Kent, R.; Guillemot, H.; Ridella, S. A.; Takhounts, E.; Martin, P. 2009. Impact response of restrained PMHS in frontal sled tests: skeletal deformation patterns under seat belt loading, SAE Technical Paper 2009-22-0001.

https://doi.org/10.4271/2009-22-0001

Wang, F; Yang, J.; Li, G. 2014. Finite element analysis of human rib fracture under various impact loading conditions, Chinese Journal of Theoretical and Applied Mechanics 46(2): 300-307. (in Chinese).

Wang, F.; Yang, J.; Miller, K.; Li, G.; Joldes, G. R.; Doyle, B.; Wittek, A. 2016a. Numerical investigations of rib fracture failure models in different dynamic loading conditions, Computer Methods in Biomechanics and Biomedical Engineering 19(5): 527-537. https://doi.org/10.1080/10255842.2015.1043905

Wang, F.; Yang, J.; Li, G.; Zhou, S.; Han, Y.; Li, F. 2016b. Numerical analysis of human thoracic injury responses in vehicle lateral and oblique crashes, Chinese Journal of Theoretical and Applied Mechanics (1): 225-234. (in Chinese).

Xiao, S.; Yang, J.; Forman, J.; Panzer, M.; Nie, B.; Crandall, J. 2015. A study on influence of seatbelt with and without force limiter to outcome of human body chest model in frontal impact test, in Proceedings of the 12th International Forum of Automotive Traffic Safety 2015, 4-5 December 2015, Xiamen, China, 329-333.

Xiao, S.; Yang, J.; Xiao, Z.; Crandall, J. R. 2017. Analysis of chest injury in frontal impact via finite element modelling based on biomechanical experiment, Chinese Journal of Theoretical and Applied Mechanics (1): 191-201. (in Chinese).

Yuen, K. F. 2009. The Development of a Numerical Human Body Model for the Analysis of Automotive Side Impact Lung Trauma. MSc Thesis. University of Waterloo, Ontario, Canada. 244 p. Available from Internet: https://uwspace.uwaterloo.ca/handle/10012/5005

Zhao, J.; Narwani, G. 2005. Development of a human body finite element model for restraint system R\&D applications, in 19th International Technical Conference on the Enhanced Safety of Vehicles (ESV), 6-9 June 2005, Washington, DC, US, 1-13. 